\title{
Nurse:patient ratios influence the achievement of oxygen saturation targets in premature infants
}

\author{
Julia Petty
}

\section{Implications for practice and research}

- Addressing optimum saturation limits is essential to limit the incidence of morbidity related to oxygen damage namely retinopathy of prematurity and chronic lung disease.

- Nurses caring for premature neonates should be mindful of the long-term consequences of neonatal care; oxygen therapy is one factor that must be considered.

- The study highlights the issue of what is the optimum saturation range in premature neonates in relation to improving outcomes for this population. This is an area still to be agreed and which is the subject of ongoing, prospective trials.

As it is not feasible to make firm links between staffing and patient outcomes based on a small study using single unit data, there is a need for this study to be replicated on a wider scale.

\section{Context}

This study investigates a potential relationship between the number of patients assigned to nurses within a neonatal intensive care unit (NICU) and the achievement of target oxygen saturation limits in premature infants. A number of studies have been undertaken to explore the link between neonatal outcomes and increased nursing workload and staffing levels.1-4 However, previous studies have not specifically studied the relationship of staffing to target oxygen levels.

\section{Methods}

This was a single centre retrospective study that collected oxygen saturation and staffing data over a 6 month period for a sample of 14 premature infants selected if less than 29 weeks gestation with available oximetry data. Data was collected for $10196 \mathrm{~h}$ time periods. 
This document is the Accepted Manuscript version of a Published Work that appeared in final form at https://doi.org/10.1136/ebnurs-2011100029, copyright (c) BMJ Publishing Group Ltd

The time during which oxygen saturations were within a specific target range (85-92\%) was recorded as well as time spent hyperoxaemic (98-100\%). The hypothesis tested was that the achievement of oxygen saturation goals would decrease with an increased number of assigned patients per nurse.

\section{Findings}

Descriptive analysis showed that mean birthweight was $860 \mathrm{~g}$, gestational age 26.6 weeks and postmenstrual age for all monitoring periods 31.6 weeks (range 24.1-40.7) with care delivered by a total of 87 nurses. Univariate regression analysis found that achievement of target saturation decreased significantly and hyperoxaemic time increased with a nurse:patient ratio of 1:2 compared with 1:1. This trend continued with the addition of a third or fourth patient (nurse:patient ratio 1:3+). In addition, more time was spent in the hyperoxaemic range as the number of patients per nurse increased. Other factors were also found to have the same relationship; as infants moved from a high to lower illness severity and as their postmenstrual age increased, the results also revealed less time in the target oximetry range and more time hyperoxaemic. Multivariate regression found that fewer patients per nurse led to significantly higher saturation target achievement for infants on high-frequency ventilation and reduced hyperoxaemia on nasal cannula $(p<0.001)$. The authors conclude that reducing the nurse:patient ratio in the NICU may result in more time within policy specified, desirable oxygen saturation ranges.

\section{Commentary}

The study has a concise and well-explained literature review including previous and current work investigating possible links between staffing and neonatal outcomes as well as those focusing on optimum oxygen saturation limits. The background, aims and chosen variables of the study design are generally described with clarity and the conclusions link effectively to areas of research that require further attention. However, the generalisability of the results is limited as this was a single centre with data based on a convenience sample of only 14 neonates. While the number of monitoring episodes was high, oximetry data were collected retrospectively and therefore the interpretation could be questioned. Many factors can affect oximetry readings causing significant and sudden 
This document is the Accepted Manuscript version of a Published Work that appeared in final form at https://doi.org/10.1136/ebnurs-2011100029, copyright (c) BMJ Publishing Group Ltd

changes such as artefact, movement, probe dislodgement, perfusion, pain and presence of a heart duct. This means

it may not be possible to link such specific physiological data with wider organisational factors. Also of note is that the target ranges are based on one unit's policy but these ranges differ to those set in other units, which vary considerably. The range of $85-92 \%$ may well be lower than practiced elsewhere so the same data in another unit could yield different conclusions. The decrease in time infants spent within target saturation ranges and the increase in hyperoxaemic time was associated with the number of assigned patients per nurse increasing, infant moving from higher to lower illness severity, increasing postmenstrual age, full ventilation to nasal cannula oxygen and from decreasing oxygen requirement. However, this may reflect the infants' conditions improving over time. Further research is needed before it is possible to conclude categorically that these findings are due solely to staffing levels

Correspondence to:

Julia Petty School of Health Sciences, City University, Philpot Street, London E1 2EA, UK; J.D.Petty@city.ac.uk

Commentary on: Sink DW, Hope SA, Hagadorn JI. Nurse:patient ratio and achievement of oxygen saturation goals in premature infants. Arch Dis Child Fetal Neonatal Ed 2011;96:F938.

\section{References}

Callaghan LA, Cartwright DW, O'Rourke $\mathrm{P}$, et al. Infant to staff ratios and risk of mortality in very low birthweight infants.Arch Dis Child Fetal Neonatal Ed 2003;88:F94-7.

Profit J, Petersen LA, McCormick MC, et al. Patient-to-nurse ratios and outcomes of moderately preterm infants. Pediatrics 2010;125:320-6.

Bell EF, Hansen NI, Morris FH Jr, et al. Impact of timing of birth and resident duty-hour restrictions on outcomes for small preterm infants. Pediatrics 2010;126:222-31.

Hamilton KE, Redshaw ME, Tarnow-Mordi W. Nurse staffing in relation to risk-adjusted mortality in neonatal care. Arch Dis Child Fetal Neonatal Ed 2007;92:F99-F103. 